\title{
O tempo é o remédio: otimismo e memória religiosa em duas narrativas
}

\section{Time is the medicine: optimism and religious memory on two narratives}

\author{
Aline de Caldas Costa dos Santos \\ Universidade Estadual do Sudoeste da Bahia (UESB) \\ $<$ alinedecaldas@gmail.com>
}

\section{Edvania Gomes da Silva}

Universidade Estadual do Sudoeste da Bahia (UESB) <edvaniagsilva@gmail.com>

\section{RESUMO}

Este artigo parte do problema da materialização de uma memória coletiva cristã em diferentes narrativas de otimismo. O estudo se insere e busca contribuir para com os estudos multidisciplinares sobre comunicação, cultura, memória e discursos. $\mathrm{O}$ recorte deste artigo recai sobre o tema "confiança no tempo", observado junto a uma narrativa literária e em um pequeno conjunto de narrativas virtuais da rede social Facebook. O estudo é exploratório, realizado por meio de revisão bibliográfica e análise do discurso. O trabalho está dividido em duas etapas: a primeira se dedica às questões ligadas ao conceito de sujeito, de acordo com Foucault, observadas no poema Os trabalhos e os dias, de Hesíodo; a segunda etapa expõe um corpus de narrativas virtuais, analisadas a partir do conceito de efeito metafórico, segundo Pêcheux, somada à identificação dos sujeitos sinalizados na primeira etapa. Os resultados mostraram que existem duas posições de sujeito otimista e diversos deslizamentos de sentido, os quais se materializam por meio da relação entre os dados do corpus e a memória coletiva cristã.

\begin{abstract}
This article starts from the problem of the materialization of a collective christian memory in different narratives of optimism. The study is inserted and seeks to contribute to the multidisciplinary studies on communication, culture, memory and discourses. The clipping of this article falls under the theme "trust in time", observed along with a literary narrative and in a small set of social narratives of the social network Facebook. The study is exploratory, accomplished through bibliographic review and discourse analysis. The work is divided in two stages: the first one is dedicated to the questions related to the concept of subject, according to Foucault, observed in the poem The works and the days, of Hesiod; The second stage exposes a corpus of virtual narratives, analyzed from the concept of metaphorical effect, according to Pêcheux, added to the identification of the subjects signaled in the first stage. The results showed that there are two positions of optimistic subject and several slides of meaning, which materialize through the relationship between the data of the corpus and the collective christian memory.
\end{abstract}

Keywords: Optimism. Memory. Discourse.

\section{Introdução}

O objetivo desse artigo é compreender a maneira como se relacionam a memória coletiva religiosa e o otimismo, a partir da descrição do objeto "confiança no tempo", indicado em duas narrativas distintas. Em um 
primeiro momento, o estudo toma a literatura como meio de observação de diferentes posições a respeito do otimismo. Em seguida, analisamos materiais compartilhados em uma rede social para identificarmos reconfigurações dessa memória coletiva.

Trata-se de um trabalho de natureza multidisciplinar, realizado com o olhar teórico da análise do discurso, sob a perspectiva francesa, ora com os aportes de Michel Foucault (2014) a respeito do "sujeito", ora com o olhar de Michel Pêcheux $(1997,2006)$ sobre a questão do "efeito metafórico".

A memória comparece no trabalho sob o viés de Maurice Halwachs (2004a, 2004b), que a toma como um objeto social, sempre na perspectiva coletiva. Se o sujeito se lembra, o faz em relação a outro sujeito, sob o estímulo do outro.

As materialidades escolhidas para observar o tema selecionado são o poema. Os trabalhos e os dias, de Hesíodo, e a rede social Facebook, mais especificamente algumas fan-pages selecionadas pelas suas produções e difusão de conteúdos de otimismo.

Ao analisarmos trechos do poema e dos posts compartilhados na referida rede social por essas páginas impessoais, identificamos uma recorrência de materiais que convergem para o tema da "confiança no tempo", que é também um traço do discurso do otimismo e da memória coletiva em diversas religiões.

São identificadas duas posições de sujeito e também alguns deslizamentos de sentido entre otimismo e memória religiosa.

\section{A respeito do otimismo e do otimista em Os trabalhos e os dias}

A abordagem ao otimismo realizada no artigo tem como referência o estudo de Schopenhauer, Aforismos para a sabedoria de vida (2009), no qual o filósofo realiza a análise de um conjunto de máximas e conhecimentos populares utilizados por várias sociedades para evitar a dor e assegurar uma vida feliz.

De acordo com Schopenhauer, há três caminhos para encontrar a felicidade: um que investe sobre o campo do ser, outro que investe sobre o ter e um terceiro que investe sobre o representar. O ser é o âmbito do intelecto e dos valores morais; o ter é o campo do patrimônio material; o representar é o setor da honra e da imagem pessoal junto aos demais membros da sociedade. O estudo de Schopenhauer mostra que investir sobre o ser é o caminho mais seguro para garantir uma vida boa, uma vida isenta dos efeitos da dor, uma trajetória na qual aquilo que se acumula não pode ser extraído do seu detentor sob nenhuma hipótese. Dessa forma, o acúmulo de conhecimentos e a disposição ao aprofundamento do campo moral levariam o homem a um estado de contentamento com a vida que o eximiriam de buscas efêmeras ou 
escapadiças, a exemplo de um conjunto de posses materiais ou uma imagem de sucesso junto à opinião alheia.

Se, no prefácio da obra, Jair Barboza apresenta a teoria otimista como a perspectiva de que "este é o melhor mundo possível", Schopenhauer, ao final da análise, refina esta teoria, acrescentando que apenas um espírito que investe no ser pode alcançar a condição de uma felicidade possível em um mundo cheio de provas e chagas como este.

Considerando essa primeira dualidade, desejamos aprofundar neste trabalho dois olhares mais sobre o otimista, tomando como fonte uma proposição presente na literatura grega:

Antes, de fato, as tribos dos humanos viviam sobre a terra sem
contato com males, com o difícil trabalho ou com penosas doenças
que aos homens dão mortes. Rapidamente em meio à maldade
envelhecem os mortais. Mas a mulher, removendo com as mãos
a grande tampa de um jarro, espalhou-os, e preparou amargos
cuidados para os humanos. Sozinha ali ficava a Antecipação, na
indestrutível morada,dentro, abaixo da boca do jarro, e para fora não
voou. Pois antes baixou a tampa do jarro por vontade de Zeus que
ajunta nuvens, o detentor da égide (Hesíodo, 2012, p. 71).

Em Os trabalhos e os dias, Hesíodo narra, entre outros, o mito de Pandora. Forjada com água e terra por Hefesto, a mando de Zeus, Pandora deve sua existência a um capricho do deus maior do Olimpo. Zeus a criou embebido do desejo de vingança contra Prometeu, aquele que ousou enganar sua inteligência e Ihe desafiou, roubando o fogo do Olimpo, entregando-o aos mortais. Pandora recebeu diversos adornos de vários deuses com o propósito de encantar aos homens por meio da beleza e, o mais destacável: recebeu também de Hermes uma má índole, com a capacidade de enganar pelas palavras e seduzir por fingimento. Pandora foi enviada a Epimeteu, irmão de Prometeu, que o advertiu quanto aos presentes de Zeus. Mas Epimeteu foi vencido pelo enorme encantamento daquela criatura; aceitou-a, inclusive com o jarro que carregava consigo.

Na passagem citada, a narrativa de Hesíodo apresenta Pandora abrindo o jarro que liberta todos os tipos de mazelas para o mundo. Entretanto, Pandora não permitiu que a "Antecipação" também se espalhasse pela Terra, tampando o jarro a tempo. O trecho do poema épico é simbólico e relevante para este estudo pois, ainda que os homens estejam, doravante, sujeitos a todos os males, não lhes foi permitido "antecipar" o futuro, saber como se desenrolará o porvir. Junto ao senso comum, ganhou ênfase a ideia de que a prisão da "Antecipação" deu surgimento à "Esperança”. Assim, diante da impossibilidade de conhecer de 
antemão os acontecimentos vindouros, e, ignorando a presença dos males que Pandora deixou fugir do jarro, difundiu-se entre os mortais a virtude de desejar um futuro melhor do que o presente.

De acordo com nota no poema de Hesíodo, o nome Prometeu significa "o que pensa antes" e Epimeteu, "o que pensa depois". Essa nomeação das personagens, relacionada com a questão da temporalidade, demarca todo um campo de agenciamento de práticas para cada sujeito. Prometeu adota uma postura precavida, pois se lembra dos acontecimentos passados e também pode prever os fatos futuros. Ele guarda a memória da fúria de Zeus em relação ao efeito de suas transgressões à ordem divina e sabe que aquele é um deus de punições. Sua apreensão diante de Pandora é resultado da "posição de sujeito" que ocupa. A respeito da posição de sujeito, recorremos a Foucault:

o sujeito do enunciado é uma função determinada, mas não
forçosamente a mesma de um enunciado a outro; na medida em
que é uma função vazia, podendo ser exercida por indivíduos, até
certo ponto, indiferentes, quando chegam a formular o enunciado;
e na medida em que um único e mesmo indivíduo pode ocupar,
alternadamente, em uma série de enunciados, diferentes posições e
assumir o papel de diferentes sujeitos (Foucault, 2014, p. 113).

Sendo o sujeito, para Foucault, uma posição que pode vir a ser ocupada por alguém em determinadas condições discursivas, temos que Prometeu, enquanto personagem apreensivo quanto ao futuro, no aguardo das penalidades divinas às suas atitudes libertárias, ocupa a posição de sujeito que se resguarda do tempo.

Já Epimeteu, aquele que se volta para o futuro, adota uma postura esperançosa, assumindo os riscos da satisfação de seus desejos no presente. Epimeteu dispensa o alerta das intenções malévolas existentes nos presentes de Zeus e não se preocupa com o porvir. A beleza de Pandora e sua aparição como um presente do Deus maior se sobressaem aos riscos da integração daquela mulher ao grupo. Epimeteu ocupa a posição de sujeito que confia no tempo.

A relação de Prometeu com o passado e com o futuro nos ajuda a compreender uma relação com a memória que caracteriza certo tipo de otimismo: no passado, ele rompeu com a memória de sabedoria e poder de Zeus; para o futuro, ele se preserva de retaliações da autoridade maior do Olimpo. Prometeu materializa um otimismo intelectual e moral. Para Prometeu, a felicidade está em evitar o mal futuro.

Mas Epimeteu se relaciona apenas com o presente. Ele deseja Pandora e a aceita deimediato. Em Epimeteu também existe um tipo de memória que sustenta um tipo de otimismo: a felicidade está no agora. As consequências das escolhas, 
se negativas, serão experimentadas e administradas posteriormente. Epimeteu ilustra um otimismo emocional, que arrisca a segurança em favor das emoções.

Assim, Prometeu constrói as condições de segurança que o protegerão da dor, enquanto Epimeteu confia no tempo e age impulsivamente, gerando riscos de dor para todos ao seu redor.

Acrescentamos, ainda a respeito do mito de Pandora, um olhar a respeito de uma memória presente em diversas narrativas religiosas e que, em alguma medida, se relaciona, e até sustenta, as duas perspectivas apresentadas acima. Em seu Tratado de História das Religiões, Eliade (1998, p. 46) comenta a existência de cosmogonias, segundo as quais um Deus maior cria o universo e se retira - o Deus otiosus - deixando em harmonia sua criação até o momento em que surge um elemento que lança o mal sobre o mundo. Esse elemento é o chamado "Trapaceiro", que Eliade (1994) explica em seu Dicionário de religiões como sendo um personagem pândego e com a habilidade do disfarce, podendo fazer-se passar por deuses ou semideuses. Segundo o autor,

há uma categoria de mitos em que o Trapaceiro age como o segundo criador do mundo ou de uma parte do mundo e desempenha, principalmente, o papel de quem põe a perder a criação da divindade suprema, introduzindo no mundo todos os males hoje existentes: a mortalidade dos homens, as dores do parto etc. (Eliade, 1994, p. 134).

Essa figura que espalha os males pela Terra se materializa na poesia grega com o mito de Pandora, no instante da abertura do jarro. Ela se materializa ainda no livro bíblico de Gênesis, no trecho em que Deus descobre que Adão comeu do fruto proibido: "comeste da árvore de que te ordenei, dizendo: não comerás dela, maldita é a terra por causa de ti; com dor comerás dela todos os dias da tua vida" (Gn, 3:17). Entre os épicos indianos, essa figura responsável pelo mal é parte essencial da dinâmica do universo. Nos Vedas, por exemplo, Brahma cria o universo, Vishnu mantém a vida e Shiva destrói o universo para que tudo se renove. Ainda na mitologia indiana, há também o Mahabharata, em que Dhuryôdhana investe na guerra até que todo um grande ciclo de disputas entre gerações seja completamente destruído.

Esse é um ponto de continuidade, melhor dizendo, de reconfiguração da dualidade entre bem e mal em diferentes momentos históricos. Ele também expõe a materialização de atualizações da memória dos dois sujeitos otimistas, destacados com a descrição de Prometeu e Epimeteu: o otimista intelectual e o otimista emocional.

De acordo com Halbwachs, é possível tomar essa lembrança como parte de um "marco social de memória". Para o referido autor, "estes marcos são - 
precisamente - os instrumentos que a memória coletiva utiliza para reconstruir uma imagem do passado de acordo com cada época e em sintonia com os pensamentos dominantes da sociedade"1 (Halbwachs, 2004, p. 10, tradução nossa). Halbwachs explica que é no campo social que o homem"evoca, reconhece e localiza" suas recordações, de modo "que o indivíduo recorda quando assume o ponto de vista do grupo e que a memória do grupo se manifesta e se realiza nas memórias individuais" ${ }^{2}$ (Halbwachs, 2004, p. 11, tradução nossa).

O sujeito otimista intelectual, materializado em Prometeu, e o sujeito otimista emocional, materializado em Epimeteu, se apresentam e se intercalam na memória coletiva a respeito da busca pela felicidade. Vejamos como esses sujeitos se mostram na segunda materialidade selecionada para este trabalho.

\section{A respeito da memória do otimista na rede social Facebook}

Seja o otimista intelectual, seja o emocional, se faz importante pontuarmos que a memória que se difunde a respeito dessas posições de sujeito, nesse estudo, é tomada enquanto uma memória coletiva.

Segundo Halbwachs,

Nossas lembranças permanecem coletivas, e elas nos são lembradas
pelos outros, mesmo que se trate de acontecimentos nos quais só nós
estivemos envolvidos, e com objetos que só nós vimos. É porque, em
realidade, nunca estamos sós. Não é necessário que outros homens
estejam lá, que se distingam materialmente de nós: porque temos
sempre conosco e em nós uma quantidade de pessoas que não se
confundem (Halbwachs, 2004b, p. 26).

Se nos lembramos, segundo Habwachs, é porque estamos em um coletivo que se lembra e que nos faz lembrar. Na obra intitulada Os marcos sociais de memória (2004a), Halbwachs apresenta um constructo teórico acerca da memória com inspiração no legado de seu mestre, Émile Durkheim, em especial, do conceito de "fato social": os marcos de memória são "exteriores", ou seja, partem do coletivo, incidindo sobre cada sujeito; tais marcos exercem um tipo de "coerção" sobre os coletivos sociais de modo a reforçar o uso padrão de certo tipo de comportamento ou visão de mundo; os marcos sociais de memória são, ainda, objetivos, pois alcançam a todo o grupo, não se reduzindo a apenas um indivíduo ou outro.

1 No original: "estos marcos son - precisamente - los instrumentos que la memoria colectiva utiliza para reconstruir uma imagem del passado acorde com cada época y em sintonía con los pensamientos dominantes em la sociedade" (Halbwachs, 2004, p. 10).

2 No original: "que el individuo recuerda cuando asume el punto de vista del grupo y que la memoria del grupo se manifiesta y se realiza em las memorias individuales" (Halbwachs, 2004, p. 11). 
Para Habwachs, sequer nos sonhos a memória se apresentaria de maneira individual. Até essas manifestações do inconsciente estão subordinadas ao uso da linguagem, que é um fato social, ou seja, possuem natureza e ação coletiva. Habwachs se dedica à análise de três instâncias sociais para sustentar sua teoria: a família, a religião e as classes sociais.

A respeito da memória coletiva religiosa, Halbwachs se refere como a que deseja estar "fora do tempo", pois busca a permanência, a imutabilidade. Assim, abordando o Cristianismo na maior parte do corpus de análise, o autor destaca que é através de ritos e celebrações, repetidas ad aeternun, que a religião rememora os fatos que devem ser lembrados sobre a vida de Jesus, com ênfase sobre seus ensinamentos. Contudo, mesmo alimentando o desejo da permanência, essa memória é atualizada. Segundo Halbwachs muitas das leituras correntes das escrituras sagradas são resultados de interpretações arbitrárias, indicando "leituras adequadas" para os pontos de divergências; eventualmente, alguns desses pontos sofrem novas alterações em reuniões posteriores das classes superiores de sua hierarquia.

Nessa etapa do trabalho, temos como objetivo verificar se as posições de sujeito identificadas na etapa anterior se recolocam, por meio de atualizações de memórias coletivas, com um plano de fundo religioso nos materiais coletados.

É caro ao estudo o conceito de "efeito metafórico" Pêcheux (1993) que se refere aos "pontos de deriva" em uma certa formulação linguística da qual um sentido usual abarca um novo sentido potencial. Trata-se de um deslizamento de sentido de um sentido manifesto para outro que também constitui a formulação linguística. Assim, buscamos pontos em que o otimismo demonstre a presença da memória religiosa nos materiais recolhidos na rede social Facebook. Segundo Pêcheux (2006) a língua é uma "estrutura", uma memória, porém, nesta estrutura é possível a incidência do que o autor chama de "acontecimento", que é quando emerge um novo, um inesperado, em meio à estrutura.

Todos os materiais que integram o corpus são oriundos de perfis impessoais da rede social em questão. Conhecidas como "fan-pages", esses espaços virtuais são isentos de autoria, assinando cada conteúdo disponibilizado com o mesmo título da página. A seleção das páginas foi realizada com o auxílio do mecanismo de pesquisa da rede social, no qual buscamos por "otimismo" e visitamos as páginas com maior número de "curtidores" e alta frequência na difusão de conteúdos. Aqui, três fan-pages compuseram o corpus: Hierophant, Caminho de otimismo e Otimismo, alegria e esperança.Sempre (sic.).

Destacamos o material colhido na fan-page intitulada Hierophant. O post apresenta o número de 1.057 compartilhamentos e 665 curtidas. É composta pela formulação linguística: “Da vida eu só espero rir dos tombos, aprender com 
os erros, e continuar acreditando que no final tudo vai dar certo". Associada ao texto, vemos a imagem de uma flor que libera suas frágeis pétalas ao vento.

\section{Figura1}

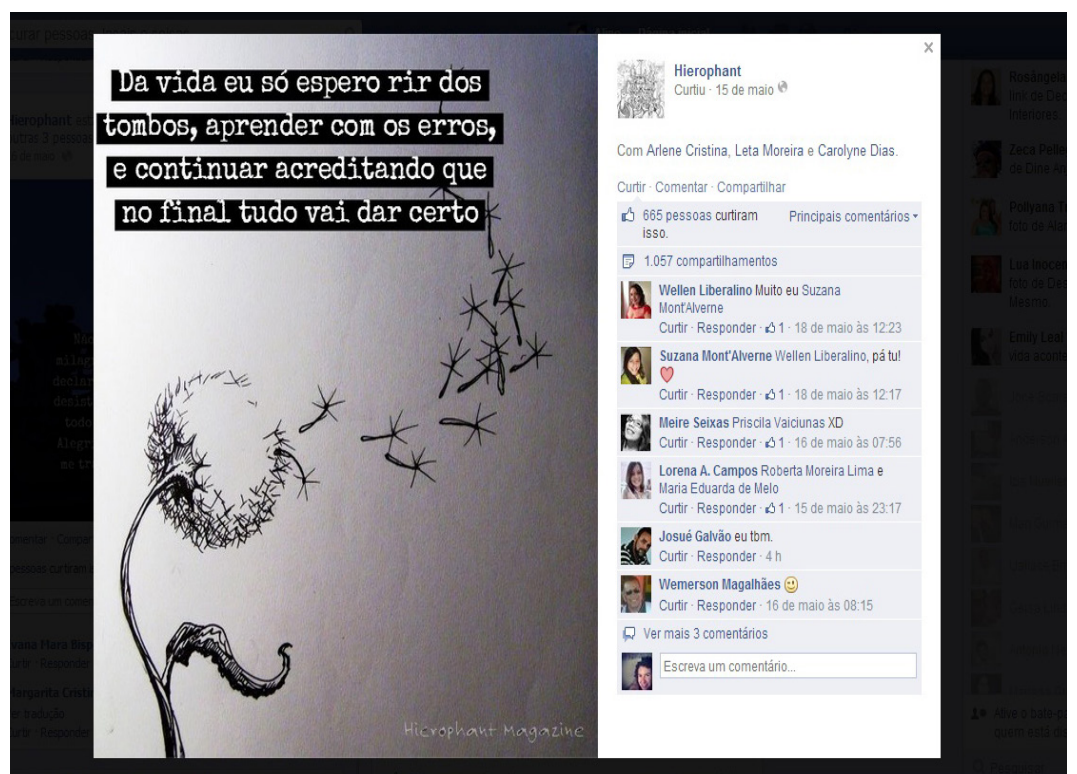

Fonte: Hierophant, Facebook

Como disciplina interessada pelo sentido, a Análise do Discurso coopera para compreender o material acima como uma referência à renovação da vida, pois a imagem da flor que solta suas pétalas ao vento, pode ser associada, por uma relação entre memória e atualidade, à ideia de uma vida que se esvai em função das vidas que virão. Isso porque as pétalas voando promovem a leitura de que, ainda que a flor deixe de existir, quando suas pétalas alcançarem solo fértil, estas permitirão o surgimento de novas plantas. Esse efeito de sentido é reatualizado/reforçado pela formulação linguística que acompanha a imagem.

O enunciado verbal instaura um enunciador otimista ("eu só espero...") que materializa em seu enunciado o discurso da não preocupação com os obstáculos, mas da confiança na passagem do tempo. Esse discurso encontrase materializado nas expressões "rir dos tombos"; "aprender com os erros", e "continuar acreditando que no final tudo vai dar certo", as quais indicam se tratar de um sujeito otimista emocional. Ele aceita esvair-se em situações de dor em favor da alegria de viver intensamente e deixar seu exemplo de intensidade de vida para os demais. 
Aquele último enunciado, "continuar acreditando que no final tudo vai dar certo", cria um pressuposto segundo o qual essa crença no futuro sempre existiu, pois o verbo "continuar" mostra que o enunciador já acreditava antes do momento da enunciação. Apesar de recorrer ao pronome pessoal "eu", o enunciado não aparece como vinculado ao momento da enunciação, pois, o "eu" marca não uma pessoa específica, mas um não-lugar, que pode ser assumido por qualquer um que se subjetive no lugar do otimista.

Isso remete ao que Foucault diz acerca do conceito de posição sujeito, pois compreende o sujeito como um âmbito transitório, um espaço de fala, uma posição ou papel a ser vivido, o que se afasta sobremaneira do indivíduo, do sujeito pragmático, do autor empírico.

Ainda em relação ao post, podemos verificar um deslizamento de sentido na direção da memória coletiva cristã. Em um primeiro momento, identificamos uma continuidade com a memória presente na Carta de Paulo aos Romanos, onde se lê "não se amoldem ao padrão deste mundo, mas transformem-se pela renovação da sua mente, para que sejam capazes de experimentar e comprovar a boa, agradável e perfeita vontade de Deus" (Rm, 12:2). A memória coletiva que emerge dessa passagem indica a confiança no tempo, que é onde reside a "vontade de Deus". Aceitar a dor de desfazer-se no tempo como uma renovação de vida seria conhecer e alinhar-se à tradição religiosa.

Há também uma relação da imagem presente no post com a parábola do semeador, já que as pétalas da flor podem deslizar seu sentido para o de sementes, o que não apaga o sentido de pétalas, de flor, de beleza que se propaga. De acordo com Pêcheux (1993), o efeito metafórico serve, entre outras coisas, "para lembrar que esse 'deslizamento de sentido' entre $x$ e y é constitutivo do 'sentido' designado por x e y" (Pêcheux, 1993, p. 96). Em outras palavras, a flor é ao mesmo tempo flor (bela, simples, pura) e semente (renovação, perseverança, persistência). Essa cadeia parasfrástica se opõe aos "tombos" e "erros" e compõe com "rir", "aprender" e "continuar acreditando". Contudo, o efeito de sentido do post não é fruto apenas daquilo que remete ao otimismo, mas se dá na relação entre oposições e composições, apontando para o otimismo emocional presente em "rir dos tombos", "aprender com os erros" e "continuar".

O segundo dado do corpus também foi selecionado na página Hierophant. 


\section{- Figura 2}

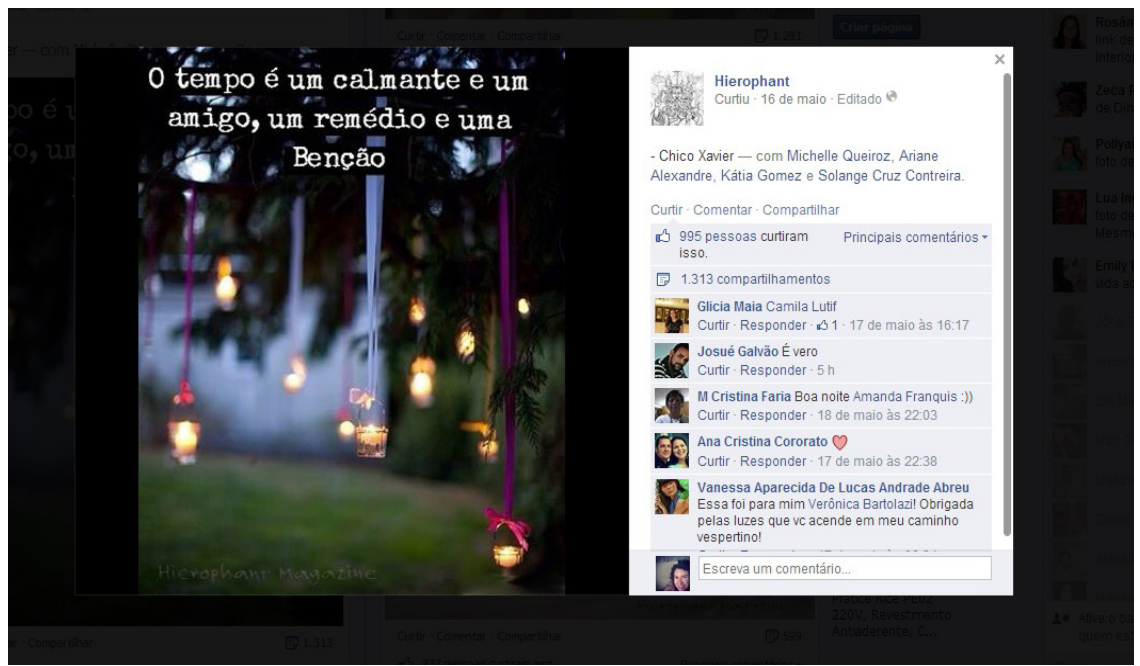

Fonte: Hierophant, Facebook

No post, temos a formulação linguística "O tempo é um calmante e um amigo, um remédio e uma Bênção" e, abaixo desta, a imagem de fundo apresenta luminárias artesanais com velas em um jardim. A postagem recebeu 995 curtidas e 1.313 compartilhamentos.

Notamos a ausência de referências ao ter e ao aparentar de que trata Schopenhauer (2009), mas identificamos uma importante indicação sobre como ser diante dos males: confiando que o tempo ajudará a acalmar, a remediar as dores e a bendizer o porvir. Há uma personificação do tempo, a qual se materializa linguisticamente por meio da expressão referencial definida "o tempo". Dessa forma, o tempo passa a ser o sujeito da oração e sobre ele incidem os predicativos "calmante", "amigo", "remédio" e "benção". Essa construção linguística permite reforçar o funcionamento do efeito metafórico, conforme definido por Pêcheux (1993), pois, por meio da relação estabelecida pelo verbo "ser", que funciona linguisticamente como cópula, a expressão "o tempo" - que aqui é o x do qual trata Pêcheux (1993, p. 96) - desliza para "um calmante", "um amigo", "um remédio" e "uma benção", e essas quatro expressões são o y de que trata Pêcheux (1993, p. 96). Nesse caso, assim como no exemplo anterior, "o 'deslizamento de sentido' entre x e y é constitutivo do 'sentido' designado por x e y" Pêcheux (1993, p. 96). Ou seja, o sentido de tempo passa também, nesse post, pelos efeitos de sentido de calmante, amigo, remédio e benção.

Ao desligar-se da perspectiva imediatista, aproximando-se de um olhar mais moral e de uma escolha racional em que o tempo se faz recurso para evitar/ 
enfrentar a dor, estamos diante de uma memória coletiva que aponta o traço do otimista racional.

Além disso, os nomes "tempo" e "benção" ligam-se a um ponto de deriva que remete à memória coletiva religiosa judaico-cristã, como mostra a seguinte citação bíblica: "Tudo fez formoso em seu tempo; também pôs o mundo no coração do homem, sem que este possa descobrir a obra que Deus fez desde o princípio até ao fim. Já tenho entendido que não há coisa melhor para eles do que alegrar-se e fazer bem na sua vida" (Ec, 3:11-12, grifos nossos). Aqui, há novamente um deslizamento de sentido entre "o tempo", do enunciado verbal do post, e "seu tempo", do texto bíblico. Nesse caso, "seu tempo" remete ao tempo de Deus, mas relaciona-se também com o sentido de "o tempo", pois cria uma relação entre "o tempo" que é "um calmante", "um amigo", "um remédio" e "uma benção" e o "tempo de Deus".

Os materiais do terceiro e do quarto posts do corpus podem ser analisados conjuntamente. Ambos foram coletados na fan-page Caminho de otimismo. Esses materiais podem ser considerados narrativas de otimismo, porque, entre outras características, se constituem com base na noção de gentileza, já que a frase inicial de cada um deles (Bom dia!) funciona como um reforço ao âmbito do ser.

Os índices de compartilhamentos e curtidas não são tão expressivos quanto os da página Hierophant, porém apresentam a formulação "Bom dia!", a qual é amplamente compartilhada em perfis pessoais da rede social em destaque. Esse cumprimento aparece quase sempre associado a imagens de plano de fundo com paisagens naturais, sejam com o nascer ou com o pôr do sol.

\section{Figura 3}

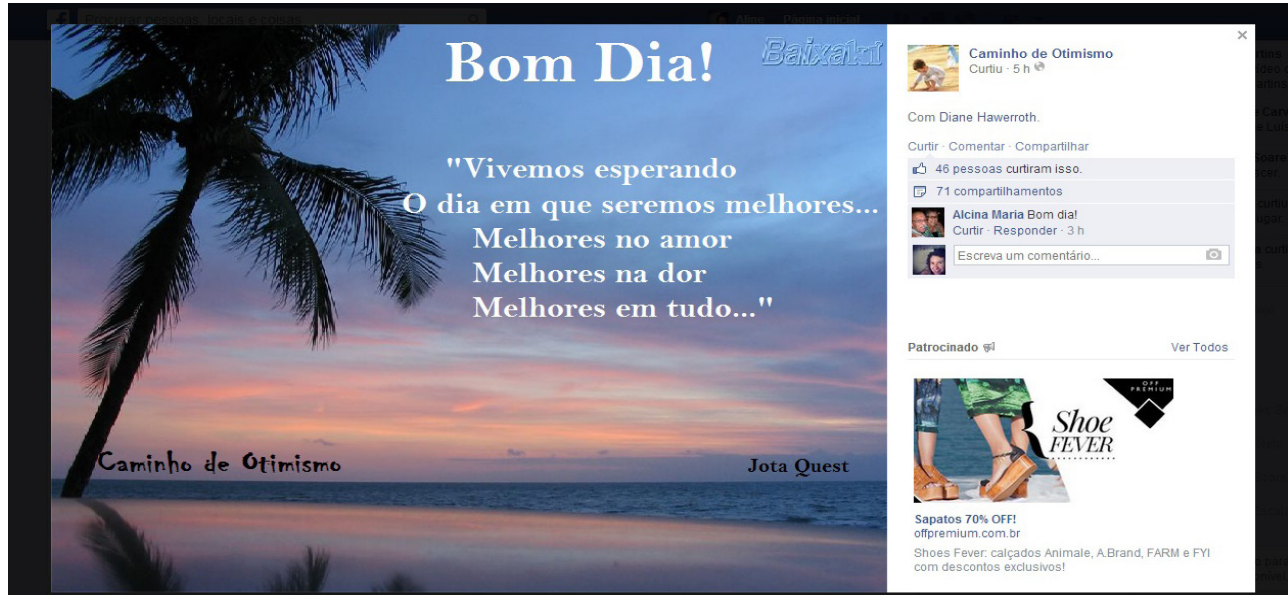

Fonte: Caminho de otimismo, Facebook 
A figura 3 apresenta um trecho de música que aponta para a confiança em tempos melhores, especialmente, em pessoas melhores. A imagem da "espera" presente na formulação linguística mantém uma relação metafórica com a passagem bíblica dos Salmos, quando aconselha:"Espera no Senhor, anima-te, e ele fortalecerá o teu coração; espera, pois, no Senhor" (27:14). Também notamos uma relação interdiscursiva com passagens bíblicas que tratam da perfeição. Como exemplo, citamos Mateus, "Sede vós, pois perfeitos, como é perfeito o vosso Pai que está nos céus" (Mt, 5:48); e a segunda carta de Paulo aos Coríntios; "Quanto ao mais, irmãos, regozijai-vos, sede perfeitos, sede consolados, sede de um mesmo parecer, vivei em paz; e o Deus de amor e de paz será convosco" (II Cor. 13:11). Do ponto de vista linguístico, a repetição de "Melhores", seguido, no primeiro caso, de "no amor", no segundo, de "na dor", e, no terceiro caso, de "em tudo", mostra uma gradação que vai daquilo que seria mais fácil (ser melhor no amor) àquilo que seria o mais nobre (ser melhor em tudo), passando pela dificuldade (ser melhor na dor), o que retoma o discurso da superação dos obstáculos e da confiança na passagem do tempo.

A figura 4 marca retoma uma memória segundo acerca dos ciclos da vida, mostrando o amanhecer como ponto de partida para alimentar esperanças. Aqui, o ponto de deriva de sentido se encontra com o livro das Lamentações, bastante presente na tradição judaica: "Bom é ter esperança, e aguardar em silêncio a salvação do Senhor" (3:26). Ainda no que diz respeito ao post, o enunciador estabelece uma relação entre a saudação (Bom dia!) e o pré-construído ${ }^{3}$ segundo o qual existe algo que pode ser definido como "A esperança". Nesse caso, a expressão referencial "a esperança" é apresentada como justificativa para que o enunciador possa expressar sua alegria, materializada pelo adjetivo "bom" e pelo ponto de exclamação, ao saudar seu co-enunciador (o leitor) com a expressão "Bom dia!"

Ainda que a citação da música e as passagens bíblicas com as quais a formulação linguística do post apresenta relação de sentido indiquem um olhar para o futuro - "o dia em que seremos melhores", "espera no Senhor", "vivei em paz", "será convosco" - o material em seu conjunto se fixa no tempo presente. Ele enraíza o leitor no "dia", na atualidade, no agora. Somado a isso, temos um sujeito que aguarda, passivo, pelo futuro feliz e repleto da graça divina. Temos novamente um otimista emocional, que confia no tempo, que aguarda, hoje, pelo dia em que a felicidade será plena e legitimada pela divindade.

3 De acordo com Pêcheux são "pré-construídos", também conhecidos como "encaixes" os "elementos citados e relatados, discursos-transversos, etc.) de que sua leitura necessita: a condição do legível em relação ao próprio legível" (Pêcheux, 2007, p. 52) 
O material abaixo também se apropria de uma imagem do nascer do sol sobre o mar, associada à saudação "Bom dia”.

\section{Figura 4}

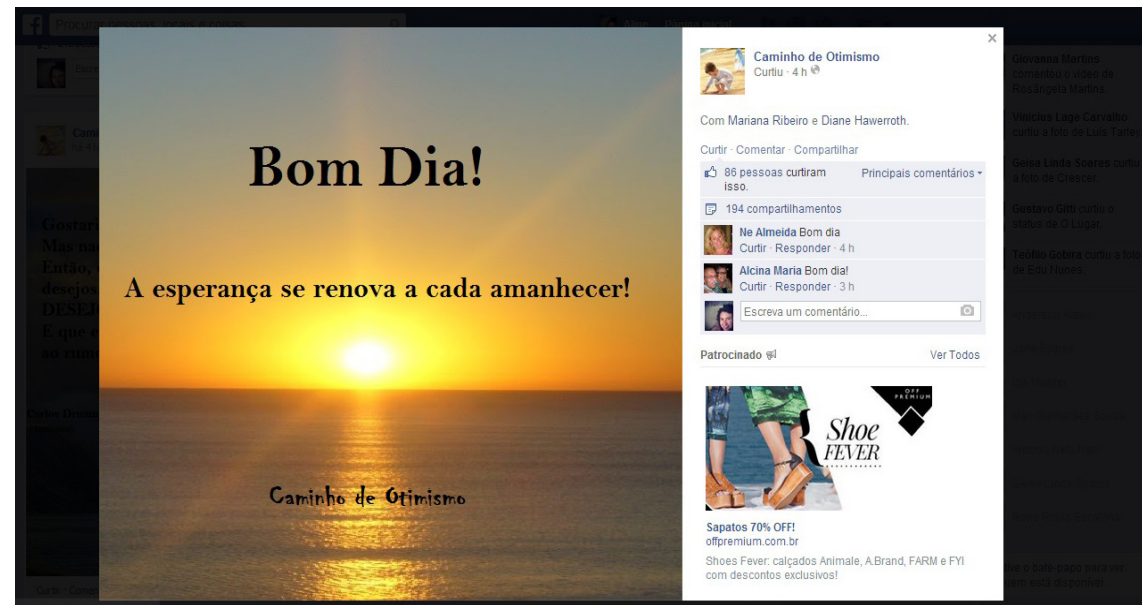

Fonte: Caminho de otimismo, Facebook

A afirmação da renovação da esperança reforça a presença do sujeito otimista emocional, que encontra a felicidade no agora, desapegando-se da memória dos acontecimentos passados em função de um olhar que valoriza os acertos confiados ao tempo.

Também no campo dos reforços, temos uma recorrência ao efeito metafórico identificado no primeiro material, materializando, novamente, o discurso da renovação das ideias, sugerida pela Carta de Paulo aos Romanos, a qual enuncia "transformem-se pela renovação da sua mente" (Rm, 12:2).

O quinto material do corpus foi coletado na página Otimismo, alegria e esperança. Sempre. Neste post, temos uma perspectiva oposta aos dois exemplos anteriores (figuras 3 e 4), pois enquanto aqueles abordavam o amanhecer (Bom dia!), esse traz como tema o encerramento do ciclo diário. Trata-se, nesse caso, de tematizar a finitude do sofrimento. Em imagem de fundo, vemos a revoada dos pássaros que prenuncia o fim das tardes; a ausência de cores e também a relação entre preto e branco presente na imagem reforçam a nebulosidade do sentimento de tristeza. 


\section{Figura 5}

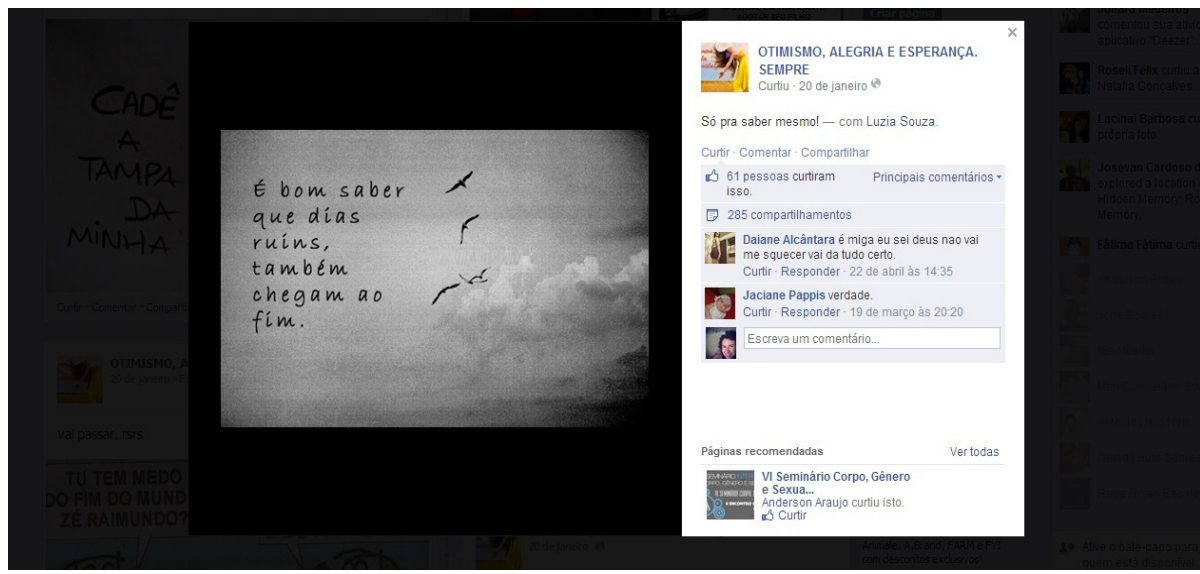

Fonte: Otimismo, alegria e esperança.Sempre. Facebook

A formulação verbal "É bom saber que dias ruins, também chegam ao fim", retoma, por meio do advérbio "também", a referência aos dias bons, os quais aparecem implicitamente no texto, como oposição aos "dias ruins". Dessa forma, o enunciador do texto reforça o discurso da superação dos obstáculos e da confiança na passagem do tempo, pois mostra que tudo passa, inclusive os dias ruins. Trata-se, portanto, de um texto que indica um olhar sobre o passado e, por meio de uma reflexão de ordem moral, sustenta um aprendizado por parte do sujeito. Assim, temos aqui a reaparição do sujeito otimista intelectual.

Ao mesmo tempo, identifica-se um efeito metafórico correlativo à memória coletiva religiosa cristã, por meio da alusão, mais uma vez, ao livro dos Salmos: "O choro pode durar uma noite, mas a alegria vem pela manhã. Eu dizia na minha prosperidade: não vacilarei jamais" (30:5-6).

O texto prioriza o ser, pois apresenta um modo de ver os acontecimentos que se constrói a partir de elementos morais, intelectuais, imateriais. A representação dos "dias ruins" se faz pelos tons cinzentos do céu, dispensando qualquer referência ao ter ou ao aparentar.

\section{Considerações finais}

As análises mostraram que, com base na Análise de Discurso, é possível tomar os materiais coletados sob a dupla perspectiva apresentada por Pêcheux: a estrutura e o acontecimento. Os materiais apresentam um sentido constituído a partir do uso de uma estrutura linguística, carregando consigo efeitos de sentido estabilizados pela língua. Porém, ao mesmo tempo, por meio do 
efeito metafórico, outros sentidos podem saltar daquela estrutura, ou daquela memória; ocorre um acontecimento, que é a emersão de um sentido "novo", também em funcionamento.

Assim, identificamos na língua o funcionamento do otimismo e, no ponto de deriva, identificamos também o efeito da memória religiosa.

Enquanto otimismo, as mensagens corroboram para a compreensão de que a felicidade não se encontra em bens materiais ou em status social, mas em uma postura que coloca o campo do ser como uma prioridade. Schopenhauer destaca este campo enquanto lugar do intelecto e da reflexão moral, o que não exclui as emoções, a subjetividade.

Em relação à memória religiosa, temos um padrão de comportamento inserido no campo do ser que, mesmo de maneira tácita, se atualiza com a circulação das narrativas de otimismo analisadas no estudo.

E ainda, no âmbito do sujeito com o qual trabalha Foucalt, temos que essas narrativas, literárias e/ou virtuais, mobilizam posições de sujeito distintas no campo do otimismo. O objeto "confiança no tempo" pode ser identificado a partir de diferentes práticas, as quais promovem o reequacionamento do próprio campo de práticas do discurso do otimismo: passiva/transformadora, emocional/intelectual, imediatista/dilatado rumo a diferentes temporalidades.

\section{REFERÊNCIAS}

BÍBLIA de Jerusalém. São Paulo: Edições Paulinas, 1985.

ELIADE, M.; COULIANO, I. P. Dicionário das Religiões. São Paulo: Martins Fontes, 1994.

ELIADE, M. Tratado de História das Religiões. São Paulo: Martins Fontes, 1998.

FOUCAULT, M. A arqueologia do saber. 7. ed. Rio de Janeiro: Forense Universitária, 2014.

HALBWACS, M. Los marcos sociales de la memória. Anthropos Editorial; Concepción: Universidad de la Concepción; Caracas: Universidade Central de Venezuela, 2004a.

A memória coletiva. São Paulo: Centauro, 2004b.

HESÍODO. Os trabalhos e os dias. Curitiba: Segesta, 2012.

PÊCHEUX, Michel. Semântica e discurso: uma crítica à afirmação do óbvio. 3. ed. Campinas: Unicamp, 1997.

O discurso: estrutura ou acontecimento. 4. ed. Campinas: Pontes Editores, 2006. 
SCHOPENHAUER, Arthur. Aforismos para a sabedoria de vida. 2. ed. São Paulo: Martins Fontes, 2006.

Recebido em: 4/3/2017

Aceito em: $16 / 5 / 2017$

Dados das autoras:

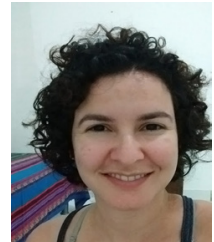

Aline de Caldas Costa dos Santos | alinecaldas@gmail.com

Doutora em Memória: Linguagem e Sociedade (2017) pela Universidade Estadual do Sudoeste da Bahia, professora da Universidade Federal do Oeste da Bahia. Tem experiência na área de Teorias da Comunicação, Comunicação e cultura, Cultura popular e patrimônio imaterial.

Universidade Estadual do Sudoeste da Bahia (UESB)

Estrada do Bem Querer, km 4

45083-900 - Vitória da Conquista (BA) - Brasil

Edvania Gomes da Silva | edvaniagsilva@gmail.com

Possui Pós-Doutorado em Linguística pela Universidade Estadual de Campinas (2010), Doutorado em Linguística (2006) e Mestrado em Linguística (2004) pela mesma instituição e Graduação em Letras pela Universidade Federal de Pernambuco (2002). Durante a Graduação, foi bolsista de Iniciação Científica pelo CNPq. Atualmente, é Professora Titular da Universidade Estadual do Sudoeste da Bahia (UESB); docente do Programa de Pós-Graduação em Memória: Linguagem e Sociedade (CAPES / UESB) e docente do Programa de Pós-Graduação em Linguística (CAPES / UESB). Atua na área de Linguística, área de concentração em Análise de Discurso, com ênfase nos seguintes temas: discurso religioso; polêmica discursiva e interdiscurso; aforização.

Universidade Estadual do Sudoeste da Bahia (UESB)

Estrada do Bem Querer, km 4

45083-900 - Vitória da Conquista (BA) - Brasil 